\title{
Construction and Operation for Utilities Tunnel Public Project in China: An Analysis Based on G-S Interactive Finance Framework
}

\author{
Feng Sun ${ }^{1, *}$, Cheng Liu ${ }^{1}$, and Xiaoguang Zhou ${ }^{1}$ \\ ${ }^{1}$ University of Science and Technology Beijing, Donlinks School of Economics and Management, China
}

\begin{abstract}
In reality, non-profitable government organizations, other organizations or individuals (G part) and profitable social organizations or individuals (S part) usually construct and operate utilities tunnel together. As quasi public goods, utilities tunnel public project has the character of big scale construction, high investment and long recycle period. In China, utilities tunnel project is mainly fulfilled by nonprofitable government organizations and profitable social companies. This paper uses G-S interactive finance framework to analyze finance design for utilities tunnel public project in China. It also develops and deepens G-S interactive finance framework for utilities tunnel project. China's experience is useful for other countries to construct and operate utilities tunnel engineering project.
\end{abstract}

\section{Introduction}

Utilities tunnel construction belongs to an important part in urban underground space construction. By constructing corridor in some depth underground, water supply and drainage, electric power, telecommunication, gas, rubbish pipelines are laid inside. Utilities tunnel is a complicated engineering project with large scale, and its design and construction involve with many engineering profession fields. Different with traditional open-cut style for pipelines, utilities tunnel can avoid resource wasting and inconvenience to society, because traditional open-cut style need dig the ground many times. It can also decrease safety questions and can repair timely for pipeline obstacle[1-5].

Because utilities tunnel has more advantages than traditional open-cut style, the project will improve the sustainable development level of cities[6-10]. After long term research and improvement, its technology is very mature and many countries have constructed tunnel projects now[11-14]. The utilities tunnel kilometers per thousand people in some cities are: Stockholm 2.1, Tokyo 2, Osaka 2, Madrid 1.6, Taiwan 1.3, Moscow 1.2, China 0.24[15]. Data shows that comparing with other countries, China has less utilities tunnel kilometers per thousand people. China will have a wide development prospect for utilities tunnel in the future.

Utilities tunnels are generally fulfilled as public projects in China, and they belong to urban management infrastructure. It has the character of noncompetitiveness and exclusiveness. Non-competitiveness means that one pipeline using unit won't affect the usage of another pipeline using unit. Exclusiveness means that managing unit for utilities tunnel public project can charge to pipeline using units, and can exclude those pipeline using units if they don't pay the fee.

Because of quasi public goods attributes for utilities tunnel public project, it can't allocate resources individually by market mechanism. It belongs to a field of market failure. The supply of this quasi public goods should be mainly guided by government sector. Government sector should macroscopically adjust and control resources allocation to fulfill the function and efficiency for utilities tunnel public project.

This paper uses a new type G-S interactive finance framework for analysis. It also develops and deepens G$\mathrm{S}$ interactive finance framework to analyze construction and operation development for utilities tunnel public project in China. China's fulfillment style can give useful experiences for other countries to construct and operate utilities tunnel engineering project.

\section{G-S interactive finance framework for utilities tunnel public project in China}

Generally, there are three finance types for utilities tunnel project. First, all the construction and operation finance is supported only by non-profitable organizations or individuals. Second, all the construction and operation finance is supported only by profitable organizations or individuals. Third, all the construction and operation finance is supported by non-profitable organizations or individuals and profitable organizations or individuals together[16].

To fully make use of the resources for utilities tunnel public project, this quasi public goods can be supplied individually by government sector, and its cost can be 
spent from government finance incomes. It can also be supplied by cooperation of government sector and social capital. In this mode, government sector should mainly guide and social capital should cooperate. Because utilities tunnel has big scale construction, high investment amount and long recycle period, it will create much finance expenditure pressure to government sector if government sector affords total investment individually. This is not good to timely supply the public project. So government sector and social capital should supply utilities tunnel public project together.

In reality, non-profitable government organizations, other organizations or individuals ( $\mathrm{G}$ part) and profitable social organizations or individuals ( $\mathrm{S}$ part) usually construct and operate utilities tunnel together. In China, the project is mainly fulfilled by non-profitable government sector and profitable social companies.

Government sector and social companies can design rational G-S interactive finance framework to acquire high efficiency and good economic revenue. G-S interactive finance framework is a new type analysis angle for utilities tunnel project[16]. It analyzes the finance design from the cooperation between nonprofitable organizations or individuals and profitable organizations or individuals. This paper uses G-S interactive finance framework to analyze finance design for utilities tunnel public project in China. It also develops and deepens G-S interactive finance framework for utilities tunnel. Different with non-profitable organizations or individuals and profitable social organizations or individuals in the past, this paper uses non-profitable organizations or individuals, profitable social companies and other social organizations or individuals to analyze the finance bodies. Profitable social companies manage the construction and operation for the public project to make a living, and they have abundant technology and management experiences for project. Other social organizations or individuals take part in the project only as an investment way.

Assume during construction period for the public project in China, the financial capital is from $i\left(i=1,2 \cdots n_{G}\right) \quad$ non-profitable government organizations(other non-profitable organizations or individuals can also be included in G part), and No.i government organization invests $I_{G i}\left(I_{G i}>0\right)$. The financial capital is also from $j_{1}\left(j_{1}=1,2 \cdots n_{s 1}\right)$ profitable social companies and from $j_{2}\left(j_{2}=1,2 \cdots n_{s 2}\right)$ other profitable social organizations or individuals. No.j, social company invests $I_{S j_{1}}$, and $N o . j_{2}$ other social organization or individual invests $I_{S j_{2}}\left(I_{S j_{1}}>0, I_{S j_{2}} \geq 0\right)$. $I_{S j_{2}}=0$ means No.j $j_{2}$ other social organization or individual doesn't invest, and the public project is supplied by government organizations and social companies.
During construction period, the finance weights of $\mathrm{G}$ part and $S \operatorname{part}\left(\omega_{S 1}\right.$ is social companies, and $\omega_{S 2}$ is other social organizations or individuals) are:

$$
\begin{aligned}
& \omega_{G}=\sum_{i=1}^{n_{G}} I_{G i} \quad\left(0<\omega_{G}<1\right) \\
& \overline{\sum_{i=1}^{n_{G}} I_{G i}+\sum_{j_{1}=1}^{n_{i 1}} I_{S j_{1}}+\sum_{j_{2}=1}^{n_{G 2}} I_{S j_{2}}} \\
& \sum_{i=1}^{n_{S 1}} I_{S j_{1}} \quad\left(0<\omega_{S 1}<1\right) \\
& \omega_{S 1}=\frac{\sum_{j_{1}=1}^{n_{S i}} I_{S i} I_{G i}+\sum_{j_{1}=1}^{n_{1}} I_{S j 1}+\sum_{j_{2}=1}^{n_{i} 2} I_{S j 2}}{\sum_{i=1}} \\
& \sum_{i_{2}=1}^{n_{S 2}} I_{S j 2} \quad\left(0 \leq \omega_{S 2}<1, \omega_{G}+\omega_{S 1}+\omega_{S 2}=1\right) \text {. }
\end{aligned}
$$

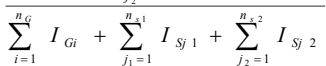

Operation period is usually long and assume there are $T_{\gamma}$ periods $(\gamma=1,2 \cdots m)$. During $T_{\gamma}$ period, No.i government organization invests $F_{G i T_{y}}\left(F_{G i T_{y}} \geq 0\right) \cdot$ No.j. social company and No.j $_{2}$ social organization or individual invest $F_{S_{j} T_{\gamma}}$ and $F_{S_{2} T_{\gamma}}$,respectively $\left(F_{S_{j} T_{\gamma}} \geq 0, F_{S_{j} T_{y}} \geq 0\right)$. The capital discount rate is $R_{T_{\gamma}}$. Assume that $P$ and $Q_{T_{\gamma}}$ are service price and service number of utilities tunnel.

Then the net revenue of utilities tunnel is $B_{T_{y}}-C_{T_{y}}$ :

$$
B_{T_{\gamma}}-C_{T_{\gamma}}=\left(P-C_{Y T_{y}}\right) Q_{T_{\gamma}}+\sum_{i=1}^{n_{G}} F_{G i T_{y}}+\sum_{j_{1}=1}^{n_{s i}} F_{S_{j} T_{\gamma}}+\sum_{j_{2}=1}^{n_{s 2}} F_{S j_{2} T_{\gamma}}-C_{X T_{y}} .
$$

Assume that net revenue is continuous distribution function among interval $\left[a_{T_{y}}, b_{T_{\nu}}\right]$, and $f(\bullet)$ is probability density function. Then cumulative probability distribution function is:

$$
F\left(X_{T_{\gamma}}\right)=P\left(X \leq X_{T_{\gamma}}\right)=\int_{a_{T_{\gamma}}}^{X_{T_{\gamma}}} f(X) d X .
$$

Net revenue expectation is:

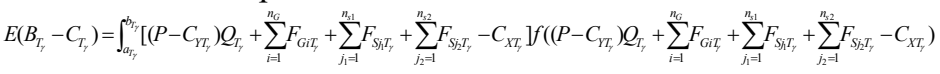

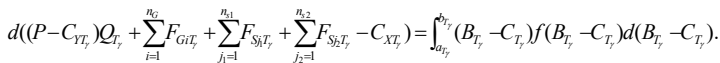

Net revenue variance is:

$$
V\left(B_{T_{\gamma}}-C_{T_{\gamma}}\right)=E\left(B_{T_{\gamma}}-C_{T_{\gamma}}-\int_{a_{T_{\gamma}}}^{b_{T_{\gamma}}}\left(B_{T_{\gamma}}-C_{T_{\gamma}}\right) f\left(B_{T_{\gamma}}-C_{T_{\gamma}}\right) d\left(B_{T_{\gamma}}-C_{T_{\gamma}}\right)\right)^{2}
$$

For one utilities tunnel public project, government organizations and social companies should cooperate and adopt rational management measures to increase net revenue expectation $E\left(B_{T_{y}}-C_{T_{y}}\right)$. Because net revenues are different in different periods, the volatility levels are also different. To acquire stable net revenue for utilities tunnel public project, government organizations and social companies should adopt rational measures to decrease the variance $V\left(B_{T_{T_{\gamma}}}-C_{T_{r}}\right)$.

To measure volatility risk and find out abnormal high risk periods for utilities tunnel public project, the varying coefficient should be used. The absolute value of varying coefficient can be computed as follows: 


$$
V C_{T_{\gamma}}=\left|\frac{V\left(B_{T_{\gamma}}-C_{T_{\gamma}}\right)}{E\left(B_{T_{\gamma}}-C_{T_{\gamma}}\right)}\right| \cdot
$$

If $V C_{T_{y}}$ value is high in one period, it shows the volatility risk is big in this period. Government organizations and social companies should analyze and find out the influence factors to create so high ${ }_{V C_{T_{S}}}$ value.

The total revenue $\mathrm{W}$ for utilities tunnel during construction period and operation period is:

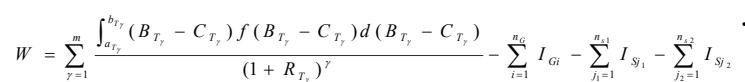

Assume that $Q=F(P)$. Then extreme optimal solution $P^{*}$ for utilities tunnel is satisfied with:

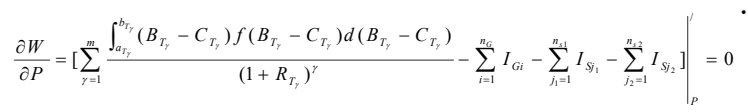

Extreme optimal solution $Q^{*}$ is satisfied with:

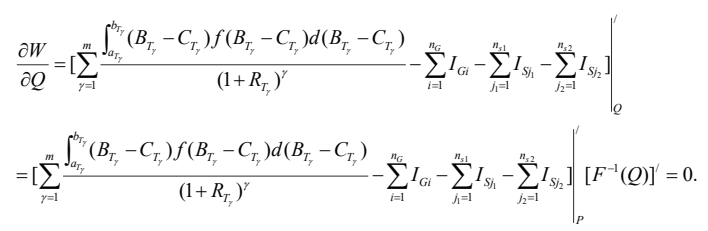

During $T_{\gamma}$ period, No.i government organization gets revenue ${ }_{D_{G i T_{s}}}$, and ${ }_{N o . j_{1}}$ social company and ${ }_{N o . j}$ other social organization or individual get revenue ${ }_{D_{S_{i} T_{x}}}$ and ${ }_{D_{S S_{i} T_{s}}}$. Then the revenue proportions of government organizations and social companies are:

$$
\begin{aligned}
& \sum_{\gamma=1}^{m} \sum_{i=1}^{n_{n}} D_{G i r_{\gamma}} /\left(1+R_{T_{f}}\right)^{\prime}
\end{aligned}
$$

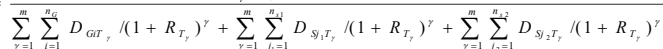



The investment revenue $H_{G}$ of government organizations and the investment revenue $H_{S 1}$ and $H_{S 2}$ of social companies and other social organizations or individuals are:

$$
\begin{gathered}
H_{G}=\sum_{\gamma=1}^{m} \sum_{i=1}^{n_{G}} \frac{D_{G i T_{\gamma}}}{\left(1+R_{T_{\gamma}}\right)^{\gamma}} /\left(\sum_{i=1}^{n_{G}} I_{G i}+\sum_{\gamma=1}^{m} \sum_{i=1}^{n_{G}} \frac{F_{G i T_{\gamma}}}{\left(1+R_{T_{\gamma}}\right)^{\gamma}}\right) \\
H_{S 1}=\sum_{\gamma=1}^{m} \sum_{j_{1}=1}^{n_{s 1}} \frac{D_{S_{j} T_{\gamma}}}{\left(1+R_{T_{\gamma}}\right)^{\gamma}} /\left(\sum_{j_{1}=1}^{n_{s 1}} I_{S j_{1}}+\sum_{\gamma=1}^{m} \sum_{j_{1}=1}^{n_{s 1}} \frac{F_{S S_{1} T_{\gamma}}}{\left(1+R_{T_{\gamma}}\right)^{\gamma}}\right) \\
H_{S 2}=\sum_{\gamma=1}^{m} \sum_{j_{2}=1}^{n_{s 2}} \frac{D_{S_{j_{2}} T_{\gamma}}}{\left(1+R_{T_{\gamma}}\right)^{\gamma}} /\left(\sum_{j_{2}=1}^{n_{s 2}} I_{S j_{2}}+\sum_{\gamma=1}^{m} \sum_{j_{2}=1}^{n_{s 2}} \frac{F_{S j_{2} T_{\gamma}}}{\left(1+R_{T_{\gamma}}\right)^{\gamma}}\right) \\
H_{S 1}>H_{S 2} .
\end{gathered}
$$

Because social companies need manage construction and operation for utilities tunnel public project, its revenue rate $H_{S 1}$ should surpass revenue rate $H_{S 2}$ of other social organizations or individuals.
The investment revenue $H_{G i}$ of No.i government organization and the investment revenue $H_{S_{j_{1}}}$ of $N o \cdot j_{1}$ social company are:

$$
\begin{aligned}
& H_{G i}=\sum_{\gamma=1}^{m} \frac{D_{G i T_{\gamma}}}{\left(1+R_{T_{\gamma}}\right)^{\gamma}} /\left(I_{G i}+\sum_{\gamma=1}^{m} \frac{F_{G i T_{\gamma}}}{\left(1+R_{T_{\gamma}}\right)^{\gamma}}\right) \\
& H_{S j_{1}}=\sum_{\gamma=1}^{m} \frac{D_{S_{j}, T_{\gamma}}}{\left(1+R_{T_{\gamma}}\right)^{\gamma}} /\left(I_{S_{j_{1}}}+\sum_{\gamma=1}^{m} \frac{F_{S_{j}, T_{\gamma}}}{\left(1+R_{T_{\gamma}}\right)^{\gamma}}\right)
\end{aligned}
$$

\begin{tabular}{|c|c|c|c|}
\hline $\begin{array}{l}\text { profitable } \\
\text { social } \\
\text { companies }\end{array}$ & $0<\omega_{S 1}<1$ & $\begin{array}{c}H_{S 1}>0 . \\
H_{S 1} \text { should surpass } \\
\text { aim revenue rate. } \\
H_{S 1} \text {-floating value } \\
\text { according to } \\
\text { performance. }\end{array}$ & $\begin{array}{c}\text { Max. } E\left(B_{T_{\gamma}}-C_{T_{\gamma}}\right) \\
\text { Min. } V\left(B_{T_{\gamma}}-C_{T_{\gamma}}\right) \\
\text { Min. } V C_{T_{\gamma}} \\
W>0 \\
\frac{\partial^{2} W}{\partial Q^{* 2}}<0\end{array}$ \\
\hline $\begin{array}{c}\text { other } \\
\text { profitable } \\
\text { social } \\
\text { organizations } \\
\text { or } \\
\text { individuals }\end{array}$ & $0 \leq \omega_{s 2}<1$ & $\begin{array}{c}H_{S 2}>0 . \quad H_{S 1}>H_{S 2} \\
H_{S 2} \text { should surpass } \\
\text { aim revenue rate. } \\
H_{S 2} \text {-constant value. }\end{array}$ & \\
\hline
\end{tabular}

The main character of G-S Interactive Finance Framework for Utilities Tunnel Public Project in China is listed in Table 1.

Table 1. G-S Interactive Finance Framework for Utilities Tunnel Public Project in China

\begin{tabular}{cccc}
\hline $\begin{array}{c}\text { Finance } \\
\text { bodies }\end{array}$ & $\begin{array}{c}\text { Finance } \\
\text { weights }\end{array}$ & $\begin{array}{c}\text { Investment } \\
\text { revenue }\end{array}$ & Project revenue \\
\hline $\begin{array}{c}\text { non- } \\
\text { profitable }\end{array}$ & $\begin{array}{c}0<\omega_{G}<1 \\
\left(\omega_{G}+\omega_{S 1}+\omega_{S 2}=1\right)\end{array}$ & $\begin{array}{c}H_{G}>0 . \\
H_{G} \text { should surpass }\end{array}$ \\
$\begin{array}{c}\text { government } \\
\text { organizations }\end{array}$ & & aim revenue rate. &
\end{tabular}

\section{G-S interactive finance framework analysis for project development in China}

The first Chinese utilities tunnel public project was built in Beijing in 1958. The public projects were built with big scale in the early stage of 21 century. According to data statistics, 69 cities in China began to construct utilities tunnel public projects about 1000 kilometers in 2015. Its total investment was about 88 billion RMB. The utilities tunnel public projects length was rapidly developed to about 6,600 kilometers until December, 2017. Among plans of city construction, the new main roads and new industrial parks should construct utilities tunnel projects in the future[17]. China government pays more attention to construct infrastructure in cities, and construction and operation for utilities tunnel public projects will be developed in more cities. Utilities tunnel public projects will have wide development prospect.

Utilities tunnel public project has the character of big scale construction and high investment, that is, the total investment $\sum_{i=1}^{n_{G}} I_{G i}+\sum_{j_{i}=1}^{n_{1}} I_{S_{i}}+\sum_{j_{2}=1}^{n_{22}} I_{S_{i}}$ is high. Generally, the total investment will be mainly supported by government organizations and social companies. Government 
organizations investment $\omega_{G}$ and social companies investment $\omega_{S 1}$ are most of proportion for total investment. $\sum_{i=1}^{n_{G}} I_{G i}+\sum_{j=1}^{n_{B_{1}}} I_{S_{j_{1}}}+\sum_{j_{2}=1}^{n_{L_{2}}} I_{S_{j_{2}}}$ mainly includes the building and installation expense for the tunnel and additional engineering projects, and operation cost $C_{Y T_{Y}} Q_{T_{y}}+C_{X T_{y}}$ mainly includes running, maintenance, renewal expense[18]. According to the character of utilities tunnel public project, it is very important to design rational construction and operation mechanism. For both government organizations and social companies, rational investment proportion, construction and operation duty and right should be regulated. Fig. 1 lists the cooperation mechanism between government organizations and social companies for the public project in China.

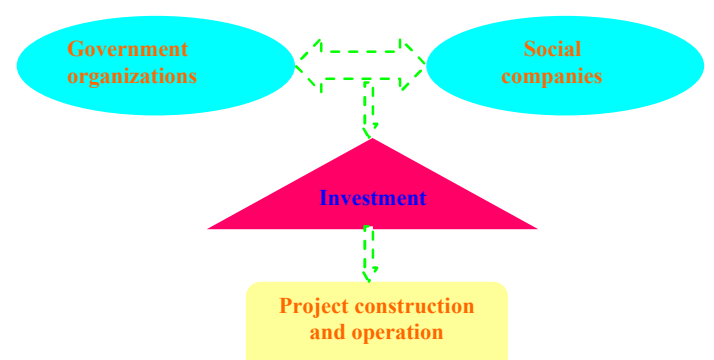

Fig. 1. Cooperation mechanism between government organizations and social companies for utilities tunnel public project in China.

For a long time, the construction and operation for utilities tunnel public project had been done by government organizations individually. Because of incomplete information for government organizations, the efficiency and function for utilities tunnel public project couldn't be completely fulfilled. In 2014 the government proposed to adopt franchise, investment bonus and government purchasing service styles to encourage social capital to invest utilities tunnel public projects in cities. The government also proposed to try government organizations and social companies cooperation for utilities tunnel public project. In 2015 the government proposed to amplify government organizations and social companies cooperation to encourage social capital to build project corporation to take part in construction and operation for utilities tunnel public project. According to data statistics, there were 515 utilities tunnel projects to be built in 2017, among which about half projects had adopted government organizations and social companies cooperation. Now government organizations and social companies cooperation has been widely used in the operation for utilities tunnel public projects.

According to detailed status for utilities tunnel public project, government organizations and social companies cooperation can flexibly adopt many different styles. Franchise BOT(build-operate-transfer) is typical operation style, and many styles can be created based on BOT. If utilities tunnel public project adopts BOT style, government organizations will give this public project to social companies to design and construct. Social companies have license of certain franchise period after this public project has been built. During franchise period, No.j social company operates utilities tunnel public project and can get revenue $H_{S_{j_{i}}}$ from ${ }_{B_{T_{\gamma}}}-C_{T_{y}}$, and $H_{S_{1}}$ should surpass its aim revenue rate. When franchise period is over, social companies will transfer utilities tunnel public project to government with no returns.

\section{G-S interactive finance framework analysis for project operation management in China}

As quasi public goods, utilities tunnel public project has the character of big scale construction, high investment and long recycle period. To build utilities tunnel public project, it is necessary to dig in some depth underground to build one way, two ways or multi ways corridors. The light, ventilation, supervision, telecommunication and other systems need to be built inside the corridors. So the construction cost for utilities tunnel public project is high. To acquire timely high $\sum_{i=1}^{n_{G}} I_{G i}+\sum_{j=1}^{n_{i k}} I_{S_{i}}+\sum_{j_{i}=1}^{n_{S_{2}}} I_{S_{2}}$ for utilities tunnel public project, government organizations and social companies cooperation can be used.

The investment revenue $H_{G i}$ of No.i government organization and the investment revenue $H_{S j_{1}}$ of No.j social company should both surpass their aim revenue rates. Because other social organizations or individuals take part in project only as an investment way, the investment revenue ${ }_{H_{S 2}}$ can be designed as a constant value, which is more than corresponding bank deposit rate. Because social companies manage construction and operation for project, the investment revenue ${ }_{S 1}$ can be designed as floating value according to performance.

Utilities tunnel public project should adopt all life cycle management mode to improve efficiency for the construction and operation of utilities tunnel public project. In all life cycle management mode, the design, construction, operation and supervision for utilities tunnel public project are managed together to fully make use of every stage's character and to balance every stage's development to realize high efficiency running and economic revenue. The total revenue should satisfy:



Government organizations and social companies should adopt rational measures to increase $\mathrm{W}$ value. Rational extreme optimal solution $P^{*}$ and $Q^{*}$ should be adopted. Assume that there is unique extreme optimal solution, then $\mathrm{W}$ should satisfy:

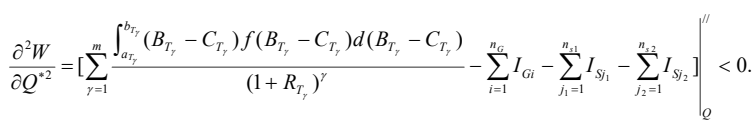


If $W>0$, the total revenue ${ }_{W\left(Q^{*}\right)}$ will arrive at maximum profit value. If $W<0$, the total revenue ${ }_{W\left(Q^{*}\right)}$ will arrive at minimum loss value.

During design stage for utilities tunnel public project, the district status, engineering condition, finance and expense should be fully considered. The needs for pipeline using units and maintenance should also be fully considered. The design, engineering, operation and supervision sides must coordinate each other to improve running efficiency in all life cycle for public project.

For the construction and operation for utilities tunnel public project, the realization of investment revenue for government organizations and social companies should be fully considered. As quasi public goods, utilities tunnel public project not only can acquire economic revenue, but also can acquire social benefits. Nonprofitable government organizations should fully consider the realization of investment revenue for profitable social organizations or individuals. During operation periods for utilities tunnel public project, the net revenue ${ }_{B_{T_{\gamma}}-C_{T_{r}}}$ should first compensate the constant value revenue $H_{S 2}$ of other social organizations or individuals. Then the net revenue ${ }_{B_{T_{y}}-C_{T_{y}}}$ should compensate the floating value revenue $H_{S 1}$ of social companies. If it is not enough for ${ }_{H_{S_{i}}}$ of $N_{N o j_{1}}$ social company to surpass aim revenue rate, government organizations can give extra bonus to social companies.

Rational investment recycle and profit style for social companies should be designed. For example, the profit style for France government organizations and social companies cooperation mainly includes three types. First, directly charge to terminal consumers. Second, pay the total fee by public finance or country tax, that is, government sector pays the total fee. Third, mix the two modes and repay the fee in many periods[19]. To get the investment of social companies timely for the construction of utilities tunnel public project, many channels of profit mode should be designed for social companies. During operation period, utilities tunnel public project can charge the fee entering into tunnel and daily maintenance fee to pipeline using units. Some measures can be flexibly adopted to increase the activeness of social companies.

\section{Conclusions}

The Chinese utilities tunnel projects are usually fulfilled as public projects and belong to urban management infrastructure. They have the character of noncompetitiveness and exclusiveness. Because utilities tunnel public projects have big scale construction, high investment and long recycle period, government organizations and social companies should supply utilities tunnel public projects together.

In reality, non-profitable government and other organizations or individuals ( $G$ part) and profitable social organizations or individuals ( $\mathrm{S}$ part) usually construct and operate utilities tunnel project together. This paper uses G-S interactive finance framework to analyze finance design for utilities tunnel public project in China. It also develops and deepens G-S interactive finance framework for utilities tunnel project.

Government organizations and social companies cooperation can flexibly adopt many different styles, among which franchise BOT is typical operation style. During the construction and operation period, utilities tunnel public project should adopt all life cycle management mode to improve the efficiency. When utilities tunnel public project uses government organizations and social companies cooperation, the investment revenue for government organizations and social companies should be fully considered.

\section{References}

1. J. Canto-Perello, J. Curiel-Esparza, V. Calvo, Exp. Syst. Appl. 40, 4707-4714 (2013)

2. J. Canto-Perello, J. Curiel-Esparza, Tunn. Undergr. Space Technol. 33, 82-87 (2013)

3. L. Legrand, O. Blanpain, F. Buyle-Bodin, Tunn. Undergr. Space Technol. 19, 79-83 (2004)

4. J. Canto-Perello, J. Curiel-Esparza, V. Calvo, Tunn. Undergr. Space Technol. 55, 146-152 (2016)

5. O. Špačková, J. Šejnoha, D. Straub, Tunn. Undergr. Space Technol. 37, 62-78 (2013)

6. J. J. Cano-Hurtado, J. Canto-Perello, Tunn. Undergr. Space Technol. 14, 335-340 (1999)

7. J. Phillips, Tunn. Undergr. Space Technol. 51, 387404 (2016)

8. D. V. L. Hunt, D. Nash, C. D. F. Rogers, Tunn. Undergr. Space Technol. 39, 15-26 (2014)

9. C. Delmastro, E. Lavagno, L. Schranz, Tunn. Undergr. Space Technol. 55, 103-111 (2016)

10. O. N. Egbunike, A. T. Potter, J. Transp. Geogr. 19, 499-508 (2011)

11. A. Glerum, Tunn. Undergr. Space Technol. 10, 455462 (1995)

12. J. Canto-Perello, J. Curiel-Esparza, Tunn. Undergr. Space Technol. 16, 211-215 (2001)

13. R. K. Goel, Tunn. Undergr. Space Technol. 16, 6375 (2001)

14. T. W. Hulme, A. J. Burchell, Tunn. Undergr. Space Technol. 14, 409-418 (1999)

15. C. Yang, F. L. Peng, Proc. Eng. 65, 540-548 (2016)

16. F. Sun, C. Liu, X. G. Zhou, Tunn. Undergr. Space Technol. 69, 182-186 (2017)

17. P. Wang, Const. Eco. 2, 113-115 (2016)

18. F. R. Liu, Chi. Inves. 15, 74-75 (2016)

19. L. Xu, Adm. La. Rev. 3, 116-127 (2016) 